\title{
Ser cidadão no Oitocentos: A atuação dos fabricantes de cal na freguesia da Ilha do Governador
}

\author{
Judite Paiva Souto ${ }^{1}$
}

\begin{abstract}
Resumo
Neste artigo, buscaremos tecer algumas considerações acerca do exercício da cidadania na freguesia da Ilha do Governador, tomando como objeto de estudo a atuação do caieiro João Rodrigues Carrilho. Integrante do Município Neutro da Corte, a freguesia de Nossa Senhora da Ajuda da llha do Governador, durante o século XIX, se destacava por sua produção de cal a partir de conchas. Os fabricantes deste material utilizado na construção civil se faziam presentes em diversas esferas da vida pública: os caieiros integravam associações beneficentes, irmandades, eram nomeados para cargos públicos e disputavam eleições a exemplo de João Rodrigues Carrilho, que foi juiz de paz, capitão da Guarda Nacional e agraciado com a Imperial Ordem da Rosa no grau de cavaleiro.
\end{abstract}

Palavras-chave: Ilha do Governador; século XIX; fabricantes de cal.

\section{Ser ciudadano en el siglo XIX: el papel de los fabricantes de cal en el barrio Isla del Gobernador}

\section{Resumen}

En este artículo tratamos ciertos aspectos del ejercicio de la ciudadanía en el barrio Isla del Gobernador, tomando como objeto de investigación la actuación del calero João Rodrigues Carrilho. Integrante del Municipio Neutro de la Corte, el barrio de Nossa Senhora da Ajuda de la Isla del Gobernador se destacaba, durante el siglo XIX, por su producción de cal a partir de conchas. Los fabricantes de este material utilizado en la construcción civil contaban con representantes en diversas esferas de la vida pública: los caleros integraban asociaciones caritativas y hermandades, eran nombrados en cargos públicos y participaban de elecciones, como João Rodrigues Carrilho, que fue juez de paz, capitán de la Guardia Nacional y condecorado con grado de caballero en la Orden Imperial de la Rosa.

Palabras clave: Isla del Gobernador; siglo XIX; fabricantes de cal.

\section{Citizenship in the 1800s: the role played by lime manufacturers in the parish of Illha do Governador}

\section{Abstract}

This article analyzes aspects of the exercise of citizenship in the parish of llha do Governador, focusing on the role played by lime manufacturer João Rodrigues Carrilho. Part of the Neutro da Corte municipality, the parish of Nossa Senhora da Ajuda da Ilha do Governador became renowned in the nineteenth century for the production of lime from shells. The manufacturers of this material used in civil construction were introduced into various spheres of public life: lime manufacturers were members of charitable associations and fraternities and were appointed to public posts, running for elections. Rodrigues Carrilho was an example of such, serving as justice of the peace and captain of the National Guard, as well as being made knight of the Imperial Order of the Rose.

Keywords: Ilha do Governador; nineteenth century; lime manufacturers.

\footnotetext{
${ }^{1}$ Mestranda do Programa de Pós-graduação em História da Universidade Federal Fluminense.

E-mail: juditepaiva@hotmail.com.
} 
Être citoyen au XIX ${ }^{\text {ème }}$ siècle: I'influence des fabricants de chaux de la circonscription d'llha do Governador

\section{Résumé}

Dans cet article, nous analyserons certains aspects de l'exercice de la citoyenneté dans la circonscription d'Illha do Governador, en prenant comme objet d'étude les actions du chaulier João Rodrigues Carrilho. Intégrée à la Municipalité neutre de la Cour, la circonscription de Nossa Senhora da Ajuda da llha do Governador s'était rendue célèbre au XIX ${ }^{\mathrm{ème}}$ siècle pour sa production de chaux à partir de coquillages. Les fabricants de ce produit utilisé dans la construction civile étaient présents dans diverses sphères de la vie publique. Ils faisaient partie d'associations caritatives et de confréries, ils occupaient des postes publics et disputaient des élections, à l'instar de João Rodrigues Carrilho, qui fut juge de paix et capitaine de la Garde nationale, sans oublier son titre de Chevalier de l'Ordre impérial de la Rose.

Mots-clés : Iha do Governador ; XIX ${ }^{\text {ème }}$ siècle ; fabricants de chaux.

\section{十九世纪的公民：州长岛教区的石灰生产者}

摘要:

本论文研究十九世纪巴西帝国里约热内卢地区的州长岛 (Ilha do Governador)

教区公民参与政治的情况, 以石灰生产商加利里奥为例(João Rodrigues Carrilho).

州长岛是国王直属管辖区, 教区名是AJUDA圣母教区, 在十九世纪主要商业活动是利用海里的贝壳生产建材 石灰。石灰生产商积极参与公共生活, 加入了慈善机构, 和教友互助会。有些人获得了官位, 参加了竞选活动 , 比如说João Rodrigues Carrilho,

他担任了治安官, 国民卫队的中队长, 被授予巴西帝国玫瑰骑士团的骑士称号。

关键词: 州长岛, 十九世纪, 石灰生产商。

$* * * * * *$

\section{Uma economia caieira}

Na segunda metade do século XIX, a principal atividade econômica da freguesia de Nossa Senhora da Ajuda da Ilha do Governador, no Município Neutro da Corte, era a produção de cal de conchas. Seus fabricantes ocuparam importantes funções públicas: foram juízes de paz, fiscais municipais, subdelegados e inspetores de quarteirão. Alguns deles foram condecorados. O presente trabalho tem por finalidade tecer algumas considerações acerca do exercício da cidadania na freguesia da llha do Governador, tomando como objeto de estudo a atuação do caieiro João Rodrigues Carrilho. 
Integrante das denominadas freguesias rurais da cidade do Rio de Janeiro, a llha do Governador apresentou importante produção de cal no oitocentos. Acerca desta atividade, foi realizado registro por Jean Baptiste Debret, que dedicou uma de suas pranchas à representação do fabrico de cal de concha em uma das ilhas da Baía de Guanabara.

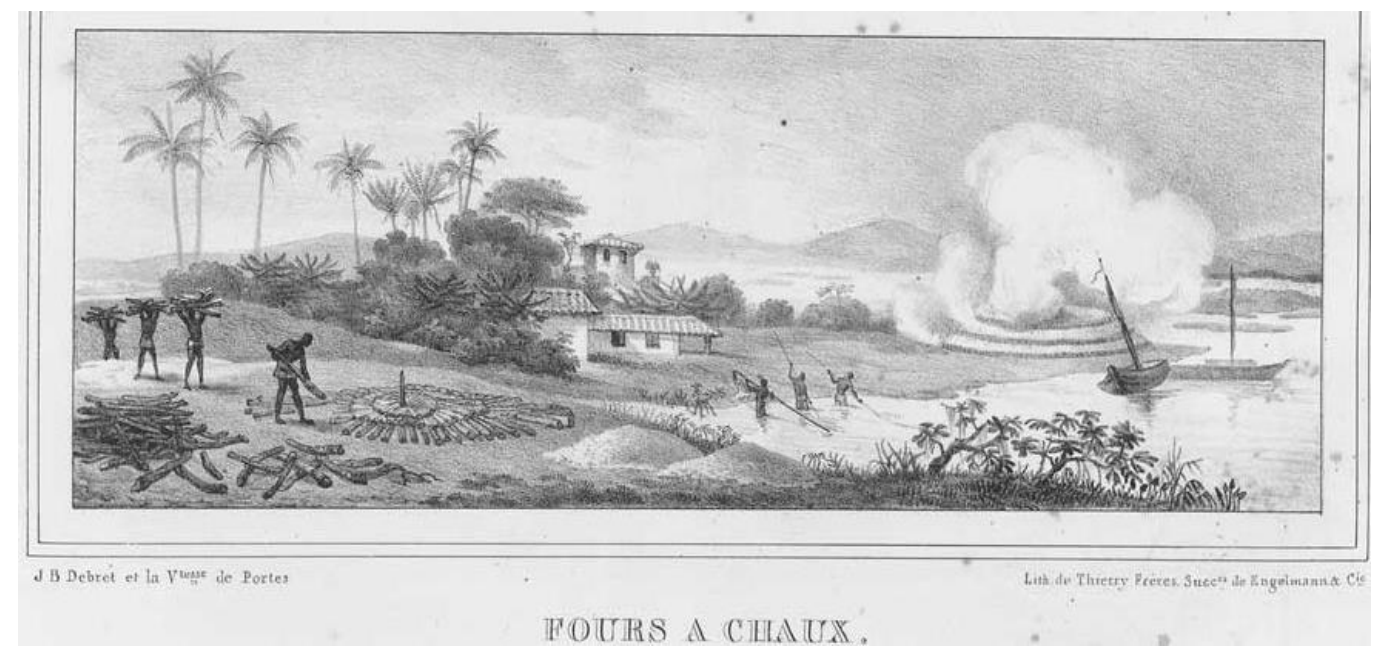

Representação de uma caieira por Jean Baptiste Debret. Debret, Jean Baptiste (1835). Prancha 35.

A gravura de Debret apresenta uma edificação envolta por vegetação em uma praia aparentemente pouco habitada, dois barcos de um mastro e sete trabalhadores ocupados em diferentes afazeres. À esquerda três homens se encarregam do transporte da lenha; ao lado, ainda à esquerda, um operário dispõe a madeira amontoada em círculo em um terreiro. No centro, outros três homens, com água na altura da cintura, munidos de uma grande barra, aparentando cerca de 3 metros de comprimento, raspam o fundo da baía e à direita em uma ponta oposta da praia, em terreno ligeiramente elevado, um grande volume de vapor ocupa a imagem.

Ao comentar a gravura, Debret afirma que de longe era possível avistar os vapores levantados por aquela produção nas ilhas da baía da Guanabara. ${ }^{2}$ As fases representadas nas primeiras décadas do século XIX não diferem muito do processo descrito nas décadas de 1870 e 1880 tanto pelo professor Antônio Estevão da Costa e

\footnotetext{
${ }^{2}$ Debret, Jean Baptiste (s.d). Viagem pitoresca e histórica ao Brasil, São Paulo: Círculo do Livro. 2 v. p. 27-
} 28. 
Cunha, ${ }^{3}$ quanto pelo engenheiro José Américo dos Santos. ${ }^{4}$ Havia primeiramente a coleta das conchas; depois a calcinação em fornos - que passaram a ser cobertos -, e em seguida a mistura com água. O pessoal necessário incluía um feitor ou administrador e de 8 a 30 operários que normalmente eram escravos do fabricante.

Por volta das 5 ou 6 horas da manhã as "barcas da casca" saíam rumo à coroa, local no mar próximo a rochedos. Utilizando uma cangola, cujo cabo media de 4 a 5 metros, semelhante a uma enxada, três ou quatro escravos raspavam a superfície da área no leito do mar "conservando o cabo em uma direção perpendicular à superfície das águas", deixando "correr a água pelos orifícios que se acham na folha da cangola" e tornavam a mergulhar 0 instrumento. $O$ procedimento era repetido exaustivamente até cerca de 2 horas da tarde, quando as cascas eram trazidas e depositadas em "montículos em frente à fábrica" a fim de serem secas ${ }^{5}$.

O material era descarregado dos barcos e amontoado em um terreiro em grandes montes, a fim de que os escravos pudessem misturá-los com carvão, formando montes menores. Em seguida, a mistura era conduzida em cestos, na cabeça dos cativos, para os fornos, os quais já deveriam conter a lenha para acender o fogo. Para auxiliar a operação, utilizava-se um ventilador, movido por uma pequena máquina a vapor, estabelecendo uma corrente contínua de ar para não faltar o oxigênio necessário à combustão do carvão. Realizada a calcinação, retirava-se o produto dos fornos, deixava-se que esfriasse e depois se misturava água proporcionalmente a seu volume para hidratação. Sua comercialização era realizada na Corte, nos subúrbios e na capital da província, a imperial cidade de Niterói. ${ }^{6}$.

Segundo o Almanak Laemmert - periódico anual que circulou de 1844 até meados do século $\mathrm{XX}$ com informações variadas sobre autoridades políticas e organização administrativa, jurídica, política, social, religiosa e cultural da Corte e Província do Rio de

\footnotetext{
${ }^{3}$ Cunha, Antônio Estevão da Costa e (1870). Notícia descritiva da llha do Governador. Arquivo Nacional. NP - Diversos Códices da Antiga SDH, Cód. 807, v. 3. p. 265-302. Antônio Estevão da Costa e Cunha, natural da Bahia, foi farmacêutico, professor primário e secundário, residente no Rio de Janeiro, colaborador da Revista Instrução Pública (1872-1874), autor de obras didáticas, tendo atuado na Instrução Pública da llha do Governador. Schueler, Alessandra (2008). "Professores primários como intelectuais da cidade: um estudo sobre produção escrita e sociabilidade intelectual (Corte imperial, 1860-1889)". In: Revista de Educação Pública, Universidade Federal do Mato Grosso, n. 17; Almanak Laemmert, 1882-1889.

${ }^{4}$ Santos, José Américo (1880). "Cal de marisco". In Revista de Engenharia, Rio de Janeiro, ano II, n. 1, p. 47, jan. Acervo Fundação Biblioteca Nacional.

${ }^{5}$ Cunha, Antônio Estevão da Costa e (1870). Op. Cit.

${ }^{6}$ Santos, José Américo (1880). Op. Cit., p. 4-7.
} 
Janeiro $^{7}$ - a freguesia da llha do Governador superava, quanto ao número de fábricas, importantes localidades fluminenses, fossem elas freguesias ou municípios.

Em 1879, no Município Neutro da Corte, 14 caieiras estavam estabelecidas na llha do Governador, 1 na freguesia de Nossa Senhora da Apresentação de Irajá e 13 na freguesia de Senhor Bom Jesus do Monte da llha de Paquetá. Ampliando-se para áreas geograficamente maiores e mais populosas, temos a cidade de Niterói com 7 caieiras e a cidade de Cabo Frio com $3 .^{8}$ As quatorze caieiras da llha do Governador certamente tinham um maior impacto econômico na vida de seus cerca de 2.856 habitantes em relação às 3 caieiras de Cabo Frio e seus cerca de 20.000 residentes. $^{9}$

Tratava-se, portanto, de uma atividade econômica cujo produto era aplicado principalmente na construção civil, voltado para o abastecimento do mercado interno e que teve como um de seus principais polos de produção a freguesia da Ilha do Governador. Seus proprietários se faziam presentes em diversas esferas da vida pública: integravam associações beneficentes, irmandades, eram nomeados para cargos públicos e disputavam eleições.

\section{Cidadania e participação política}

A cidadania pode ser entendida a partir do exercício dos direitos civis, políticos e sociais. Os direitos civis referem-se à vida, à liberdade, à propriedade e à igualdade perante a lei; os direitos políticos dizem respeito à participação do cidadão no governo da sociedade e os direitos sociais abrangem educação, trabalho, salário digno, saúde e aposentadoria. $^{10}$

No que tange aos direitos políticos cumpre lembrar que durante a maior parte do século XIX (1824 a 1881), vigoraram as eleições indiretas em dois graus. ${ }^{11}$ Primeiro os "cidadãos ativos", reunidos em "assembleias paroquiais", elegiam os "eleitores de

\footnotetext{
${ }^{7}$ Limeira, Aline de Morais (2007). Educação Particular e Publicidade no Almanak Laemmert (1844/1859), Rio de Janeiro: Fundação Biblioteca Nacional, p. 18. Disponível em: <http://www.bn.br/portal/arquivos/pdf/Aline_de_Moraes.pdf>. Acesso em: 11 out. 2013.

${ }^{8}$ Almanak Laemmert, 1879. 454, 457. Almanak Laemmert, 1879. Província. p. 28-56, 89.

${ }^{9}$ Almanak Laemmert, 1879. Província. p. 89.

${ }^{10}$ Carvalho, José Murilo (2013). Cidadania no Brasil: o longo caminho. 16. ed., Rio de Janeiro: Civilização Brasileira. p. 9-10.

${ }_{11}$ Tapajós, Vicente (Coord) (1984). Organização Política e Administrativa do Império, Brasília: FUNCEF. v. 9. p. 196-204.
} 
província"; estes, em seguida, elegiam os deputados, senadores e membros dos Conselhos Gerais das Províncias. ${ }^{12}$ Juízes de paz e vereadores, por outro lado, eram eleitos diretamente.

A quantidade de eleitores por paróquia guardava relação com o número de fogos. A cada cem destes criava-se uma vaga de eleitor. ${ }^{13}$ Até 1850 , a Ilha do Governador escolheu três eleitores. A partir de 1861, cinco e em 1876, sete. ${ }^{14}$ Para termos uma ideia do que isso representava vejamos o quantitativo geral da Corte e de outras freguesias em 1880. Comparada ao Colégio da Corte que possuía 507 eleitores e especificamente à freguesia de Santa Rita com seus 61 eleitores, os 7 votantes da llha parecem pouco significativos. No entanto, se considerarmos freguesias semelhantes, isto é, mais afastadas da área urbana, a exemplo de Irajá, Inhaúma e Paquetá, com 13, 15 e 4 eleitores respectivamente vemos que a llha não estava tão distante de outras localidades.

Se o número de eleitores da freguesia de Governador parece pequeno frente ao total do Município Neutro da Corte, isso não quer dizer que a votação fosse pacífica. Exemplo disso foram as eleições municipais de julho de 1880, marcada pela interferência de João Rodrigues Carrilho, cavaleiro da Ordem da Rosa, oficial da Guarda Nacional, proprietário de fábrica de cal, ex-eleitor e ex-juiz de paz não pareceu estar nem um pouco satisfeito com o andamento dos trabalhos eleitorais, invadindo a igreja onde se realizavam as votações e levando à suspensão da votação: ${ }^{15}$

[...] um numeroso grupo de indivíduos capitaneados pelo major João Rodrigues Carrilho, os quais, em grandes vozerias, opuseram-se a que os cidadãos continuassem a votar, agrediram em seguida os mesários, e aproveitando-se da confusão que reinou, subtraíram o alistamento dos votantes. ${ }^{16}$

A notícia é inquietante. Que circunstâncias, que disputas teriam levado Carrilho a tal intervenção no processo eletivo? Vejamos acerca deste personagem que foi um dos chefes políticos da llha do Governador.

\footnotetext{
12 Brasil. Constituição Política do Império do Brasil (25 de março de 1824). Disponível em: <http://www.planalto.gov.br/ccivil_03/constituicao/constitui\%C3\%A7ao24.htm>. Acesso em: 27 nov. 2013.

${ }^{13}$ Art. 107. Brasil. Lei n$^{0} 387$ de 19 de Agosto de 1846. Disponível em: <http://legis.senado.gov.br/legislacao/ListaPublicacoes.action?id=81146\&tipoDocumento=LEl\&tipoTexto=PU B>. Acesso em: 27 nov. 2013.

${ }_{14}$ Almanak Laemmert, 1844-1889.

${ }^{15}$ Almanak Laemmert, 1844-1889.

${ }^{16}$ Gazeta de Notícias, 02/07/1880.
} 


\section{O caso de João Rodrigues Carrilho}

Tratava-se de uma sociedade hierarquizada. No topo estava aquele grupo distinto não só pela liberdade, pela cor branca, pelo grau de instrução e pela propriedade de escravos, mas principalmente pelos vínculos pessoais que estabelecia. A busca por inserção na chamada "boa sociedade" era também uma busca por cidadania, por participação e por status. ${ }^{17}$

As estratégias de João Rodrigues Carrilho para alcançar esta "boa sociedade" foram diversas. Considerada a importância dos vínculos pessoais como marca de diferenciação, certamente suas relações familiares e sociais contribuíram para a participação em diversas associações e para o fechamento de negócios. Foi casado com Felizarda Maria da Silva Rosa, ${ }^{18}$ filha de Manoel José Rosa, juiz de paz (1849-1852, 1857-1861), caieiro, capitão da Guarda Nacional ${ }^{19}$ e cavaleiro da Imperial Ordem da Rosa. ${ }^{20}$ Ao lado do sogro, falecido em 1861, Carrilho participou da subscrição popular aberta em 1854 para a confecção da estátua equestre de D. Pedro ${ }^{21}$ e se candidatou ao juizado de paz em 1860 , tendo inclusive feito campanha para o cargo na imprensa. ${ }^{22}$

Segundo IImar Mattos, através do casamento se estabeleciam frutuosas relações entre as famílias, "preocupadas em preservar os monopólios que as distinguiam". ${ }^{23}$ Sogro e genro foram caieiros e seguramente Carrilho soube se beneficiar disto, uma vez que sua esposa parece ter herdado a fábrica de cal do pai. Felizarda Maria da Silva Rosa e o marido João Rodrigues Carrilho estiveram entre os 27 signatários do "Convênio da Cal", sendo 3 fabricantes de Niterói, 9 de Paquetá e da 15 da llha do Governador. A presença de Felizarda Rosa na convenção, assinada poucos meses após a morte de seu pai, parece ter sido uma estratégia de Carrilho para assegurar sucesso nos negócios. ${ }^{24}$

Diversas foram as notas na imprensa acerca do contrato firmado por caieiros a fim de assegurar a venda de sua produção. Pudemos acessar uma série de edições em que

\footnotetext{
${ }^{17}$ Mattos, Ilmar Rohloff de (1994). O tempo saquarema: a formação do Estado Imperial, Rio de Janeiro: Acces. p. 118.

${ }^{18}$ Correio Mercantil, 21/07/1861.

${ }^{19}$ A Actualidade, 18/01/1864.

${ }^{20}$ Almanak Laemmert, 1844-1889.

${ }^{21}$ Correio Mercantil, 09/10/1861.

${ }^{22}$ Correio Mercantil, 23/08/1860.

${ }_{23}^{23}$ Mattos, llmar Rohloff de (1994). Op. cit., p. 177.

${ }^{24}$ Correio Mercantil, 18/08/1862.
} 
constam denúncias anônimas - predominantemente -, respostas dos criticados e até mesmo uma lista dos associados negando qualquer participação nas acusações. ${ }^{25}$ Afirmava-se que o gerente do convênio não respeitava acordo estabelecido, deixando de comprar a cal de alguns proprietários, em benefício de poucos; acusava-se o agente de querer ludibriar os associados, tomando-Ihes valores em letras; entre diversos protestos.

A polêmica se estendeu durante todo o ano de 1862 nas páginas do Correio Mercantil. Como era comum no período, o espaço denominado "Publicações a pedido", destinado pelos jornais para publicações variadas mediante pagamento, foi utilizado pelos associados para ridicularizar e constranger seus desafetos pessoais. ${ }^{26}$ Sob codinomes os mais pitorescos - "A alma do demente", "O caieiro do Mangue" e "O babaquara" - até versinhos difamatórios foram divulgados.

Alguns artigos da convenção foram transcritos e analisados na imprensa com o fito de denunciar os ditos "abusos" e a suposta "má fé na sua execução". "O Orelhudo", autor da crítica, explicava que determinadas regras podiam se voltar contra os caieiros, a exemplo do artigo 15, que previa preferência àqueles que não tivessem sua cal demandada em um trimestre. No caso de serem requeridas em datas próximas quantidades de cal referentes a trimestres subsequentes, o fabricante certamente teria grande dificuldade em cumprir o contrato. Dito isso e considerando que o mais provável é que João Rodrigues Carrilho fosse o responsável pela administração da caieira da esposa, o que Ihes dava maior capacidade de produção, a participação de ambos no convênio pode ter sido uma tentativa de ampliar a demanda por cal, uma vez que a preferência de cada um seria computada individualmente.

João Carrilho certamente não estava entre os prejudicados com o convênio visto que em uma destas publicações, foi apontado como "entidade perigosa" por sua tolice: "[...] quanto a Coelho e Carrilho, são para nós duas entidades perigosas: uma, por finura, e a outra por toleima". ${ }^{27}$ Este é mais um indício de que a entrada deste fabricante com sua esposa na associação foi uma escolha vantajosa para o casal. Trata-se, portanto, de um

\footnotetext{
${ }^{25}$ Correio Mercantil, 24/05/1862; 28/05/1862; 12/06/1862; 23/07/1862; 24/07/1862; 25/07/1862 , 29/07/1862; 31/07/1862; 09/08/1862; 08/08/1862; 16/08/1862; 17/08/1862; 18/08/1862; 22/8/1862; 28/08/1862; 29/08/1862; 31/08/1862; 21/12/1862; 30/12/1862; 31/12/1862.

${ }^{26}$ Machado, Humberto Fernandes (2008). "Imprensa abolicionista e a censura no Império do Brasil". In Lessa, Mônica Leite; Fonseca, Silvia Carla Pereira de Brito. (Org.) (2008). Entre a monarquia e a república: imprensa, pensamento político e historiografia (1822-1889), Rio de Janeiro: EdUERJ. p. 247.

${ }^{27}$ Correio Mercantil, 18/08/1862.
} 
personagem controvertido em sua época, que era alvo de críticas no interior da "classe fabricante de cal", como eles próprios se denominavam.

João Rodrigues Carrilho teve aliados importantes, um deles foi seu cunhado ${ }^{28}$ Bernardo José Serrão, proprietário de uma das seis fazendas/seções da llha do Governador, residente na Ribeira, juiz de paz, subdelegado, inspetor de quarteirão, fabricante de sabão, proprietário de serraria no Zumbi, responsável por reforma na Capela do Carmo na Ribeira e proprietário de um teatro no Jequiá. ${ }^{29}$ Coincidência ou não, quando do fracasso eleitoral de Carrilho em 1878, Bernardo José Serrão teve a mesma sorte.

Carrilho esteve entre as testemunhas no casamento de Maria Augusta de Oliveira Serrão, filha de Serrão, ${ }^{30}$ sinal do bom relacionamento entre os dois. Além disso, os dois participaram da já referida subscrição popular para a confecção da estátua equestre de D. Pedro I. ${ }^{31}$ Cabe dizer que dos quinze signatários, treze eram caieiros, numa demonstração da atuação deste grupo no local. Se a participação nesta lista aponta para uma tendência conservadora, esse não parece ter sido o caminho seguido por Carrilho. Em 1864 o caieiro compunha a chapa liberal ao lado de outros 4 integrantes, como Bernardo Serrão. ${ }^{32}$ Isso significava integrar um partido político que era a "aliança de profissionais liberais urbanos com a agricultura de mercado interno e de áreas mais recentes de colonização" e se opor ao Partido Conservador, "aliança da burocracia com o grande comércio e a grande lavoura de exportação. ${ }^{33}$ Havia caieiros em ambos os partidos.

Em 1864, Carrilho recebeu a mercê de Cavaleiro da Ordem da Rosa. ${ }^{34}$ Criada em 1829 para comemorar o casamento de D. Pedro I e a princesa Amélia, esta Ordem possuía seis gradações diferentes: cavaleiro, oficial, comendador, dignatário, grande dignatário e grão-cruz. Pertenciam a ela aqueles que se distinguissem por sua fidelidade

\footnotetext{
${ }^{28}$ Correio Mercantil, 26/08/1862.

${ }^{29}$ Almanak Laemmert, 1844-1889. Em 1890 o nome Serrão foi dado à rua situada no bairro do Zumbi. DOU 08/07/1890, Seção 1, p. 26.

${ }^{30}$ A celebração foi realizada em 14 de maio de 1874. Livro de Registros de casamento da freguesia de Nossa Senhora da Ajuda da Ilha do Governador, 03/1872-04/1892. Disponível em: <http://familysearch.org/>. Acesso em: 7 abr. 2013.

${ }^{31}$ Correio Mercantil, 9/10/1861.

${ }^{32}$ Correio Mercantil, 28/06/1864.

${ }^{33}$ Carvalho, José Murilo (2010). A construção da ordem: elite política imperial. Teatro de sombras: a política imperial. 5. ed., Rio de Janeiro: Civilização Brasileira. p. 408.

34 Diário do Rio de Janeiro, 18/01/1864; Constitucional, 19 de janeiro de 1864.
} 
ao imperador e por seus serviços ao império. ${ }^{35}$ Segundo a historiadora Camila Borges da Silva:

[...] as ordens constituíram-se em um instrumento tanto de construção de elites, quanto de apoio e suporte ao regime e aos monarcas, tornando-se um importante mecanismo de funcionamento do poder régio. Sua lógica atendia não somente à promoção da imagem real como benevolente, mas também aos desejos de distinção de todos, pois significava um "presente" real e uma demonstração de "estima" por parte do monarca, de maneira que o regime se sustentava no imaginário social que concebia a sociedade como uma pirâmide. ${ }^{36}$

Carrilho buscava, portanto, integrar os estratos mais elevados da sociedade e, para tal, como todo candidato, precisou apresentar uma lista dos serviços prestados ao Estado. Recebeu como contrapartida o reconhecimento de Dom Pedro II, em cujo Reinado foram distribuídas mais de 30.000 comendas. $^{37}$

Major da Guarda Nacional em 1873, ${ }^{38}$ Carrilho buscou sua diferenciação através de "mecanismos privilegiados" para a consolidação de vínculos sociais, como a Guarda Nacional que "unia por meio de uma cadeia de hierarquias o oficial de mais baixa patente e localizado no mais distante ponto do Império ao presidente da Província e ao Ministro da Justiça". ${ }^{39}$

Além disso, Carrilho foi nomeado para o influente cargo de presidente do conselho de qualificação da Guarda Nacional em $1857,{ }^{40}$ o que lhe permitia decidir quem seria ou não classificado na reserva. Isso é significativo se considerarmos que, ao contrário do oficial, tido como figura de prestígio social, proveniente das "classes abastadas"; os soldados rasos além de não possuírem o mesmo status, se viam muitas vezes prejudicados com a convocação e buscavam protetores que lhes evitasse o afastamento dos cuidados de seus ofícios ou pequenos lotes de terra. ${ }^{41}$

\footnotetext{
35 Tapajós, Vicente (Coord.) (1984). Op. Cit., p. 314.

${ }^{36}$ Silva, Camilla Borges da (2011). "As comendas honoríficas e a construção do Estado Imperial (18221831)". In Anais do XXVI Simpósio Nacional de História - ANPUH, São Paulo, jul. p. 4.

37 Ibidem. p. 5.

${ }^{38}$ Almanak Laemmert, 1844-1889.

${ }^{39}$ Mattos, Ilmar Rohloff de (1994). Op. Cit., p. 177.

${ }^{40}$ Correio da Tarde, 24/04/1857.

${ }^{41}$ GRAHAM, Richard (1997). Clientelismo e política no Brasil do século XIX, Rio de Janeiro: Ed. UFRJ. p. 48-54.
} 
O caieiro também integrou a comissão paroquial da Sociedade Popular União e Perseverança da Ilha do Governador em $1863^{42}$ e foi presidente da sociedade Junta Paroquial de União Beneficência, na mesma freguesia, inaugurada em $1881^{43}$, durante um período em que "predominou a opção pela auto-organização, através do fortalecimento de associações de ajuda mútua", indicando um esforço de participação na sociedade insulana. ${ }^{44}$ Vale ressaltar que, como filantropia e mutualismo constituíssem categorias fluidas, as sociedades "de socorros mútuos", "filantrópicas" ou de "beneficência" chegavam a ter sua identidade questionada pelo Conselho de Estado. ${ }^{45}$ Dito isso, embora não tenhamos muitas informações acerca destas associações na Ilha do Governador, pelo menos uma delas já demonstrava em sua nomenclatura destinar-se à beneficência, o que nos leva a indagar acerca das intenções de Carrilho ao integrá-las.

Entendemos a atuação do caieiro na sociedade sob a perspectiva da reciprocidade, isto é, suas relações estavam marcadas por práticas clientelísticas que se inseriam na "economia do dom", em que o ato de beneficiar alguém, gerava, em quem o fazia, a expectativa do contradom, isto é, deveria haver uma retribuição, além da atitude de gratidão e fidelidade do beneficiado ${ }^{46}$. Como neste caso tratava-se de uma ajuda a pobres, que não poderiam retribuir economicamente, lembra o antropólogo Marcel Mauss, o contradom é recebido sob a forma de reconhecimento social de sua bondade, de poder político ou da satisfação em manter alguém em sua dependência. ${ }^{47}$ Um exemplo de reconhecimento público recebido por Carrilho pode ser identificado no Correio Mercantil de 1867, quando foi divulgado pelo vigário da freguesia agradecimento expresso a este e outros caieiros por ocasião do falecimento de sua mãe. ${ }^{48}$

No dia 9 de agosto de 1871 a igreja matriz da freguesia da Ilha do Governador sofreu incêndio que a deixou em ruínas. Cumpre lembrar que o templo era local não só de celebrações religiosas como também de reunião para trabalhos eleitorais. Poucos dias depois os moradores já estavam reunidos em prol da reconstrução da igreja, elegendo

\footnotetext{
${ }^{42}$ Diário do Rio de Janeiro, 12/02/1863.

${ }^{43}$ Gazeta de Notícias, 29/01/1881.

${ }^{44}$ Viscardi, Cláudia Maria Ribeiro (2008). Experiências da prática associativa no Brasil (1860-1880). In Topoi

- revista de história, Rio de Janeiro, v. 9, n. 16, p. 117-136, jan.-jun., p.118.

45 Ibidem. p. 120.

${ }^{46}$ Xavier, Ângela Barreto; Hespanha, António Manoel (s.d.). “As redes clientelares”. In Mattos, José (Dir.). (s.d.). História de Portugal: o Antigo Regime, Lisboa: editorial Estampa, p. 381-393.

${ }_{7}$ Mauss, Marcel (1988). Ensaio sobre a dádiva. Lisboa: Edições 70.

${ }^{48}$ Correio Mercantil, 13/03/1867.
} 
uma comissão para tal fim. Entre seus membros estava Bernardo José Serrão e João Rodrigues Carrilho. ${ }^{49}$

No campo político Carrilho não costumava se sair mal. Foi escolhido eleitor de 1857 a 1860 e de 1864 a 1875 e exerceu o cargo de juiz de paz de 1861 a $1878 .^{50}$ Ser eleitor significava não só ter o direito de escolher deputados e senadores, mas também a junta de qualificação de votantes - responsável pelo processo de formação da lista geral dos cidadãos ativos e passivos -, bem como a mesa paroquial para eleições. Já o cargo de juiz de paz implicava a responsabilidade pelas causas de até 100 mil-réis, o julgamento das infrações às posturas municipais e a competência de conceder fianças provisórias. ${ }^{51}$

É bem provável que o episódio de 1880, em que consta ter interrompido as eleições primárias, tenha tido relação com o pleito de 1878. Neste ano, foram escolhidos eleitores, juízes de paz e vereadores. Embora indicado por votação para a presidência da mesa paroquial, Carrilho acabou pedindo dispensa do cargo alegando doença.

O primeiro fato curioso de 1878 foi o desaparecimento da urna eleitoral. Superado o percalço com o uso de uma urna provisória foi dado prosseguimento à votação. A apuração das cédulas eleitorais traria mais uma particularidade: se em eleições anteriores Carrilho não recebia menos que 100 votos, apenas um foi recebido na disputa para juiz de paz e dois para eleitor. Seu cunhado, Bernardo José Serrão experimentou o mesmo fracasso, tendo obtido apenas três votos para juiz de paz. ${ }^{52}$ João Rodrigues Carrilho, seu irmão Joaquim Augusto Carrilho, Bernardo José Serrão e outros figurões que costumavam se eleger na freguesia não compareceram para as votações. ${ }^{53}$

Certamente a derrota eleitoral não foi bem recebida por Carrilho. Além de estar impossibilitado de participar das eleições para deputados e senadores e ter perdido o cargo de juiz de paz, demonstrava desprestígio e perda de controle dos cargos públicos:

[...] a medida de um homem dependia do tamanho de seu grupo de seguidores e uma eleição perdida reduziria visivelmente essa comitiva. Ser demitido por um superior no governo era tolerável, pois assim é que devia ser; mas ser rejeitado por seus próprios seguidores indicava um fracasso de liderança, força, caráter, enfim, da própria clientela. ${ }^{54}$

\footnotetext{
${ }^{49}$ Diário do Rio de Janeiro, 22/08/1871.

50 Almanak Laemmert, 1844-1889.

51 Tapajós, Vicente (Coord). (1984). Op. Cit., p. 217.

52 Almanak Laemmert, 1844-1889.

${ }^{53}$ Ata da eleição de eleitores juízes de paz e vereadores da freguesia de Nossa Senhora da Ajuda da Ilha do Governador. Arquivo Geral da Cidade do Rio de Janeiro, 64-4-4, 24/02/1878.

${ }^{54}$ Graham, Richard (1997). Op. Cit., p. 112.
} 
Em um período em que as eleições eram marcadas pela violência e pela fraude, a brusca alteração no seu número de votos levanta a suspeita de que em algum momento o pleito tenha sido manipulado. O caieiro tinha motivos para estar em disputa com os eleitores e juízes eleitos e, talvez por isso, tenha levado tamanha confusão para o pleito de 1880. Se Carrilho já estava insatisfeito com o resultado de 1878, a qualificação dos votantes de 1880 tampouco lhe agradou.

Fazia parte do processo um período para pedidos de inclusão de cidadãos que não constassem na lista dos qualificados. Em 02 de março de 1880 o major João Rodrigues Carrilho apresentou-se, "acompanhado de outros indivíduos", requerendo a inclusão de 28 votantes. Segundo o registrado na ata da junta paroquial:

Logo que foi lida a relação supra mencionada, um dos indivíduos disse que a qualificação tinha sido injusta, declarando nessa ocasião o mesário Joaquim Pereira Alves de Magalhães que se a Junta fez uma qualificação sem apreciar a justiça de todos, isso não devia importar ao suplicante, o Sr. Major Carrilho, porquanto era questão que ele não podia apreciar; tanto bastou para o reclamante, Major Carrilho, e outros começassem em altas, atrevidas e descomunais vozes, dizendo-se prejudicados em seus direitos [...] o Presidente suspendeu a sessão por meia hora. Acalmadas as questões e mais sossegado o major Carrilho, porque falava como um possesso, deliberou a Junta, depois de novamente instalada, que com exceção do cidadão Pedro Ribeiro [...] e do cidadão José Luiz Ribeiro, todos os outros constantes da mesma relação foram pela Junta mandados incluir na lista suplementar. ${ }^{55}$

Os "indivíduos" que acompanhavam o major eram provavelmente seus capangas, homens pagos para fazer valer suas ordens usando-se de violência. Se fosse preciso ameaçavam votantes de candidatos concorrentes e impediam que estes chegassem às urnas. As ocorrências de disputas entre capangas adversários, muitos deles capoeiras, não eram raras no Rio de Janeiro. ${ }^{56}$ Neste caso, perto de seus 53 anos, o major buscou estar acompanhado destes partidários que tinham grande poder de persuasão diante da junta.

A ata era lida e assinada pelos membros da junta de modo que o trabalho do escrivão era limitado não só pela formalidade que a ocasião requeria quanto pelas possíveis exigências de mesários e presidente. Ainda assim, percebemos que a vozeria

\footnotetext{
${ }^{55}$ Ata da eleição da Junta Paroquial da freguesia de Nossa Senhora da Ajuda da llha do Governador. Arquivo Geral da Cidade do Rio de Janeiro, 64-2-9, 02/03/1880.

${ }^{56}$ Carvalho, José Murilo (2013). Op. Cit., p. 34.
} 
de Carrilho e seus acompanhantes teve relação com a provocação de Joaquim Pereira Alves de Magalhães que de forma polida ou não deixou claro ao ex-juiz de paz sua impotência para influenciar nas futuras eleições. Mas quem era este que provocara Carrilho?

Joaquim Pereira Alves de Magalhães manteve caieira na praia da Freguesia de 1869 a $1891,{ }^{57}$ foi proprietário de terras no mesmo local, fiscal da freguesia (1870-1871), ${ }^{58}$ juiz de paz (1869-1872) ${ }^{59}$, 3ํ suplente de subdelegado ${ }^{60}$, eleitor $(1878-1881)^{61}$, tesoureiro da Comissão para reforma da Matriz da paróquia da llha do Governador, ${ }^{62}$ membro da comissão nomeada pela Câmara Municipal do Rio de Janeiro destinada a arrecadar donativos na llha para a festa da independência. ${ }^{63}$ Nascido por volta de 1832 , era filho de Cypriano Pereira Alves de Magalhães e Emília Rosa Correa Guedes, ela também proprietária de fábrica de cal na freguesia. $^{64}$

Magalhães residia e mantinha fábrica na mesma localidade que Carrilho, a praia da Freguesia. A proximidade pode indicar uma disputa por apoio eleitoral entre os dois. De fato, pela biografia de Magalhães, ele também buscou votos para alcançar o juizado de paz e fazer-se eleitor. Contudo, Carrilho se opôs mais diretamente a outros 2 membros da mesa: Braz Francisco de Oliveira e Antônio Oliveira Bittencourt. Isso porque na mesma ocasião em que o major pediu a inclusão de votantes, apresentou requerimentos pedindo confirmação da qualificação do primeiro na paróquia da llha do Governador e ratificação acerca da elegibilidade do segundo. Carrilho juntou, ainda, 10 assinaturas as quais segundo consta na ata, não se referiam a nenhuma autoridade da freguesia além do pároco.

Aparentemente, Carrilho, no grito, teria alcançado seu intento de incluir votantes que certamente Ihe apoiariam na eleição. Contudo, não demorou muito para que a junta demonstrasse sua intenção de não atender as exigências do major. No dia seguinte ao seu requerimento, aberta a sessão, o presidente da junta paroquial declarou que havia

\footnotetext{
57 Almanak Laemmert, 1844-1889.

${ }^{58}$ Almanak Laemmert, 1870 e 1871.

${ }^{59}$ Almanak Laemmert, 1869-1972; A Reforma, 8 de fevereiro de 1872.

${ }^{60}$ Diário do Rio de Janeiro, 15/03/1874; A Reforma, 17/03/1874; Almanak Laemmert, 1875-1879 e 1881. p. 440.

61 Diário do Rio de Janeiro, 08/08/1878; Almanak Laemmert, 1878-1881.

62 Gazeta de Notícias, 22/02/1877, 23/02/1877, 24/02/1877, 27/02/1877.

${ }^{63}$ Diário de Notícias, 10/07/1885.

${ }^{64}$ Diário do Rio de Janeiro, 02/03/1867.
} 
sido omitida na ata anterior a recusa de Carrilho em assinar o termo que trouxera, conforme lhe fora requerido. Decidiu-se, então, que o major seria convidado, por ofício, a comparecer para satisfazer a formalidade da lei.

Não sabemos ao certo em que horário Carrilho recebeu o ofício e se de fato o mesmo chegou às suas mãos. Certo é que não tendo o mesmo comparecido até as quatro horas do dia 3 de março de 1880, resolveu a junta reconsiderar a decisão que incluiu os votantes solicitados "por não ser o nós - abaixo - assinado documento comprobatório para a inclusão dos referidos indivíduos". Curioso é que no dia seguinte Pedro José Soares apresentou-se à junta requerendo inclusão de cidadãos e foi prontamente atendido. ${ }^{65}$

De fato, o Decreto 6097 de 12/01/1876 ${ }^{66}$, que versava sobre a qualificação de votantes, previa em seu artigo 37 que "queixas, reclamações ou denúncias, serão reduzidas a termo, que será assinado pelo cidadão que as apresentar". Entretanto, este Decreto não estipulou prazo para assinatura o que nos faz crer que não havia impedimento legal para que se desse um tempo maior a fim de que o reclamante se apresentasse e suprisse a exigência da mesa.

Como era de se imaginar, o major Carrilho não se elegeu juiz de paz em 1880. Dentre os quatro vencedores estava Joaquim Pereira Alves de Magalhães com 170 votos. Contudo, ao lado de seu nome, no livro com o resultado das eleições, constava a seguinte anotação: "declarou pela imprensa ter renunciado ao cargo". ${ }^{67} \mathrm{O}$ caieiro que enfrentara João Rodrigues Carrilho, mesmo habilitando-se para o juizado de paz renuncia ao cargo. Depois de conquistar tantos votos, isso não parece ser apenas uma coincidência.

Houve recurso a fim de que a eleição de 1880 fosse anulada. Por pelo menos duas vezes os juízes se declararam suspeitos para julgar o petitório. ${ }^{68}$ Se por um lado não pudemos acessar a decisão do processo, por outro percebemos que o episódio parece ter sido perfeitamente contornado pelo major, tendo em vista sua participação na eleição da junta paroquial de qualificação realizada em dezembro do mesmo ano. Joaquim Pereira

\footnotetext{
${ }^{65}$ Ata da eleição da Junta Paroquial da freguesia de Nossa Senhora da Ajuda da llha do Governador. Arquivo Geral da Cidade do Rio de Janeiro, 64-2-9, 04/03/1880.

${ }^{66}$ O Decreto 6.097 de 12/01/1876 trouxe instruções regulamentares para a execução do Decreto 2.675 de 20/01/1875.

${ }^{67}$ Lista de vereadores e juízes de paz (1881-1884). Eleição de 01/07/1880. Arquivo Geral da Cidade do Rio de Janeiro, 65-1-24.

${ }^{68}$ Gazeta de Notícias, 19/09/1880; 24/09/1880.
} 
Alves de Magalhães; Vicente Lúcio de Carvalho, presidente da mesa em 1880 e Germano Mendes Limoeiro, eleito juiz de paz no mesmo pleito, não compareceram sob alegação de moléstia. João Rodrigues Carrilho foi eleito mesário e $1^{\circ}$ substituto do presidente da mesa, o Vigário Francisco Alves da Costa e Silva. A qualificação ocorreu sem quaisquer incidentes. $^{69}$

Em 1882, Carrilho foi nomeado para o posto de subdelegado, cargo estreitamente vinculado ao governo central e que desde a reforma do Código Penal de 1841 recebera diversas atribuições antes pertencentes aos juízes de paz. Em 1883 acumulava as atribuições da polícia e o anteriormente perdido juízo de paz. Chefes de polícia, delegados e subdelegados eram os principais agentes dos presidentes provinciais para 0 fornecimento de informações políticas. Subdelegados não recebiam salários sendo que a maior parte buscava esses cargos públicos "para exercer autoridade extra e estender favores, isenções e proteção aos apadrinhados", nas palavras de Richard Graham. Parece-nos que Carrilho buscava com seu cargo o já conhecido poder da polícia de "fazer as eleições", empregando subdelegados e inspetores de quarteirão, seus subordinados, para intimidar a população no período eleitoral. ${ }^{70}$

Além disso, Carrilho também buscou participar do Tribunal do Júri, forma de participação direta e intensa no Poder Judiciário, visto que havia duas sessões por ano, cada uma de 15 dias. ${ }^{71}$ Neste espaço, todavia, não pode intensificar sua atuação, tendo pedido dispensa em 1882 por motivo de doença e falecido em 12 de junho de 1883, aos sessenta anos. ${ }^{72}$

João Rodrigues Carrilho casou-se com a filha de um proeminente morador da llha do Governador, associou-se a outros fabricantes de cal em convênio, foi eleitor, ocupou o cargo de juiz de paz e quando se viu ameaçado não hesitou em fazer uso da violência. $A$ abordagem de alguns aspectos de sua vida ilustra não só a variedade de estratégia de inserção de um fabricante de cal na chamada "boa sociedade" como também a acirrada disputa pelo poder político em uma das freguesias do Município Neutro da Corte.

\footnotetext{
${ }^{69}$ Atas da qualificação de votantes da freguesia de Nossa Senhora da Ajuda da Ilha do Governador. Arquivo Geral da Cidade do Rio de Janeiro, 64-4-7, 1/12/1880-30/12/1880.

${ }^{70}$ Graham, Richard (1997). Op. Cit., p. 87, 124.

${ }^{71}$ Carvalho, José Murilo (2013). Op. Cit., p. 37.

72 Gazeta de Notícias, 14/09/1882; Livro de Registro de óbitos da Freguesia de Nossa Senhora da Ajudada Ilha do Governador, 03/1883- 09/ 1891.
} 


\section{Fontes documentais}

\section{Fontes Manuscritas}

Ata da eleição de eleitores juízes de paz e vereadores da freguesia de Nossa Senhora da Ajuda da Ilha do Governador. Arquivo Geral da Cidade do Rio de Janeiro, 64$4-4,24 / 02 / 1878$.

Ata da eleição da Junta Paroquial da freguesia de Nossa Senhora da Ajuda da Ilha do Governador. Arquivo Geral da Cidade do Rio de Janeiro, 64-2-9, 02/03/1880, 04/03/1880.

Atas da qualificação de votantes da freguesia de Nossa Senhora da Ajuda da Ilha do Governador. Arquivo Geral da Cidade do Rio de Janeiro, 64-4-7, 1/12/1880-30/12/1880.

Cunha, Antônio Estevão da Costa e (1870). Notícia descritiva da Ilha do Governador. Arquivo Nacional. NP - Diversos Códices da Antiga SDH, Cód. 807, v. 3. p. 265-302.

Lista de vereadores e juízes de paz (1881-1884). Eleição de 01/07/1880. Arquivo Geral da Cidade do Rio de Janeiro, 65-1-24.

Livro de registros de casamento da freguesia de Nossa Senhora da Ajuda da llha do Governador, 03/1872-04/1892. Disponível em: <http://familysearch.org/>. Acesso em: 7 abr. 2013.

Livro de registros de óbitos da Freguesia de Nossa Senhora da Ajuda da Ilha do Governador, 03/1883 - 09/ 1891. Disponível em: <http://familysearch.org/>. Acesso em: 7 abr. 2013.

\section{Fontes Impressas}

A Actualidade, 18/01/1864. Acervo Fundação Biblioteca Nacional.

Almanak Laemmert. 1844-1889. Disponível em: <http://www.crl.edu/brazil/almanak>. Acesso em: 13 maio 2013.

Brasil. Decreto 6.097 de 12/01/1876. Disponível em: <http://www2.camara.leg.br/legin/fed/decret/1824-1899/decreto-6097-12-janeiro-1876588003-norma-pe.html>. Acesso em: 10 out. 2013.

Brasil. Lei $\mathrm{n}^{0} 387$ de 19 de Agosto de 1846. Disponível em: $<\mathrm{http}$ ://legis.senado.gov.br/legislacao/ListaPublicacoes.action?id=81146\&tipoDocumento= LEI\&tipoTexto=PUB $>$. Acesso em: 27 nov. 2013. 
Gazeta de Notícias, 02/07/1880; 29/01/1881; 14/09/1882. Acervo Fundação Biblioteca Nacional.

Constitucional, 19 de janeiro de 1864. Acervo Fundação Biblioteca Nacional.

Constituição Política do Império do Brasil (25 de março de 1824). Disponível em: http://www.planalto.gov.br/ccivil_03/constituicao/constitui\%C3\%A7ao24.htm. Acesso em: 27/11/2013.

Correio Mercantil de 21/07/1861; 9/10/1861; 23/08/1860; 18/08/1862; 24/05/1862; 28/05/1862; 12/06/1862; 23/07/1862; 24/07/1862; 25/07/1862; 29/07/1862; 31/07/1862; 09/08/1862; 08/08/1862; 16/08/1862; 17/08/1862; 18/08/1862; 22/8/1862; 26/08/1862; 28/08/1862; 29/08/1862; 31/08/1862; 21/12/1862; 30/12/1862; 31/12/1862, 28/06/1864, 13/03/1867. Acervo Fundação Biblioteca Nacional.

Correio da Tarde, 24/04/1857. Acervo Fundação Biblioteca Nacional.

Diário do Rio de Janeiro, 12/02/1863; 18/01/1864; 02/03/1867;05/04/1870; 22/08/1871; 08/08/1878. Acervo Fundação Biblioteca Nacional.

Diário de Notícias, 10/07/1885.

Debret, Jean Baptiste, 1768-1848 (1835). Voyage pittoresque et historique au Brésil. Tome II. Paris: Firmin Didot Fréres, Imprimers de L'Institut de France. Disponível em: <http://www.brasiliana.usp.br/bbd/handle/1918/00624520\#page/1/mode/1up>. Acesso em: 12 maio 2013.

Debret, Jean-Baptiste (s.d). Viagem pitoresca e histórica ao Brasil, São Paulo: Círculo do Livro. 2v.

Diário Oficial da União, 08/07/1890, Seção 1, p. 26.

Gazeta de Notícias, 29/01/1881; 22/02/1877; 23/02/1877; 24/02/1877; 27/02/1877; 19/09/1880; 24/09/1880.

A Reforma, 17/03/1874.

Santos, José Américo (1880). "Cal de marisco". In: Revista de Engenharia, Rio de Janeiro, ano II, n. 1, p. 4-7, jan. Acervo Fundação Biblioteca Nacional.

\section{Referências}

Carvalho, José Murilo de (2013). Cidadania no Brasil: o longo caminho. 16. ed., Rio de Janeiro: Civilização Brasileira. 
(2010). A construção da ordem: elite política imperial. Teatro de sombras: a política imperial. 5. ed, Rio de Janeiro: Civilização Brasileira.

Graham, Richard (1997). Clientelismo e política no Brasil do século XIX, Rio de Janeiro: Ed. UFRJ.

Limeira, Aline de Morais (2007). Educação Particular e Publicidade no Almanak Laemmert (1844/1859), Rio de Janeiro: Fundação Biblioteca Nacional. Disponível em: <http://www.bn.br/portal/arquivos/pdf/Aline_de_Moraes.pdf>. Acesso em: 11 out. 2013.

Machado, Humberto Fernandes (2008). "Imprensa abolicionista e a censura no Império do Brasil". In: Lessa, Mônica Leite; Fonseca, Silvia Carla Pereira de Brito. (Org.) (2008). Entre a monarquia e a república: imprensa, pensamento político e historiografia (1822-1889), Rio de Janeiro: EdUERJ.

Mattos, Ilmar Rohloff de (1994). O tempo saquarema: a formação do Estado Imperial, Rio de Janeiro: Acces.

Mauss, Marcel (1988). Ensaio sobre a dádiva, Lisboa: Edições 70.

Schueler, Alessandra (2008). "Professores primários como intelectuais da cidade: um estudo sobre produção escrita e sociabilidade intelectual (Corte imperial, 1860-1889)". In Revista de Educação Pública, Universidade Federal do Mato Grosso, n. 17.

Silva, Camilla Borges da (2011). "As comendas honoríficas e a construção do Estado Imperial (1822-1831)". In Anais do XXVI Simpósio Nacional de História - ANPUH, São Paulo, jul.

Tapajós, Vicente (1984). História administrativa do Brasil: organização política e administrativa do império, Brasília: FUNCEP.

Brasília: FUNCEF. v.9.

(Coord) (1984). Organização Política e Administrativa do Império,

Viscardi, Cláudia Maria Ribeiro (2008). "Experiências da prática associativa no Brasil (1860-1880)". In Topoi - revista de história, Rio de Janeiro, v. 9, n. 16, p. 117-136, jan.jun.

Xavier, Ângela Barreto; Hespanha, António Manoel (s.d). "As redes clientelares". In: Mattos, José (Dir.) (s.d). História de Portugal: o Antigo Regime, Lisboa: editorial Estampa. p. 381-393. 